\title{
State-of-the-art in the Study of Urban Land Subsidence
}

\author{
Aihong ZHOU ${ }^{1,}$, Zhiguang $\mathrm{LI}^{1, \mathrm{~b}}$, Chao $\mathrm{YIN}^{1, \mathrm{c}}$, Ying YUAN ${ }^{1, \mathrm{~d}}$ \\ Shijiazhuang University of Economics, Shijiazhuang, 050031, P.R.China \\ aemail:sensiblecall@163.com, bemail:lizhg1978@126.com, cemail:robinyc@126.com, \\ demail:yuanyingson@163.com
}

Keywords: state-of-the-arts; land subsidence; engineering construction; geological hazard

\begin{abstract}
State-of-the-arts in the study of urban land subsidence in our country, including its occurrence mechanism, prediction and control have been reviewed in recent years. The land subsidence is a geological hazard with a reduction of regional elevation owing to the compact of soil which is given rise to the natural and human factors. It is found that the engineering construction is getting more and more impact on land subsidence. The relationship between the construction characteristics, such as the size of buildings, the volume ratio and the degree of dispersion, and land subsidence was revealed, which is helpful to the environmental protection and the sustained development of the city.
\end{abstract}

\section{Introduction}

Since first occurred in 1898, the land subsidence has become a common widespread geological disaster in the world. According to statistics, more than 60 countries and regions around the world have occurred land subsidence. In China, more than 70 cities or regions have occurred land subsidence, it has caused more than 4 billion in direct economic losses [1][2]. The disasters caused by land subsidence seriously affect the urban construction and economic development, which give rise to building damage, underground pipeline cracking, increase in maintenance costs of flood defenses, seawater intrusion and soil stalinization [3][4].

The land subsidence is one of the geological disasters with a reduction of regional elevation due to the compact of soil resulted in the natural factors and human product activities. It is of great significance for the human survival and production and has been the key research field, focused on by the international academia [2][5][6].

The reason for the land subsidence mainly include neotectonics, developing and using underground fluid resources, underground solid minerals mining, karst collapse, melting of permafrost and engineering construction[7][8].In recent years, scholars have been done a lot of research works on the occurrence mechanism, the prediction and the control of land subsidence, especially for the urban land subsidence which is also the topic discussed here, but there are still many problems need to be tackled.

\section{The mechanism of land subsidence}

\section{The deficiencies of traditional land subsidence model.}

The traditional view is that the ground subsidence in most cities in China is caused by excessive exploitation of groundwater. The mechanism of ground subsidence caused by groundwater exploitation is the effective stress principle and the principle of water dynamic consolidation. That is to say, with the decrease of the water head, the effective stress increases, and the deformation of the soil mass is generated, which leads to the land subsidence[9][10][11][12].But since 1990s, the groundwater level in the central city of Shanghai city is basically unchanged, and the land subsidence is significantly increased. At the same time, Shanghai has carried out large-scale urban construction, to the end of 2009, the rail line length of the track rises from $15.21 \mathrm{~km}$ in 1996 to 355 $\mathrm{km}$ nowadays, and the housing construction areas of more than 8 layers buildings in the city increases from $9.59 \times 106 \mathrm{~m}^{2}$ to $2.04 \times 108 \mathrm{~m}^{2}$. Similar phenomenon in the eastern city of China is more common. The traditional water flow model and the subsidence model can model the land 
subsidence caused by groundwater exploitation, but it is difficult to explain this [9][13].

The coupling effects of groundwater exploitation and building load on land subsidence.

The correlation analysis between the urban land subsidence and the construction engineering shows that the acceleration of the land subsidence is related to the urbanization construction [13]. The subsidence factors caused by the process of urbanization include the construction load and traffic load, the soil compression owing to excavation, precipitation and tunnel construction, tunnel leakage, reduce in the groundwater recharge from the surrounding areas, and the continued to decline in underground water level induced by building block water effect[13][14][15][16]. Groundwater exploitation has not been the main cause of land subsidence. The construction of large scale cities is an important cause of settlement, and the engineering settlement accounts for about $30-40 \%$ of the total land subsidence[13][17][18].With the development of urbanization in China, the proportion of engineering settlement in the ground subsidence will continue to increase.

In order to explain the urban land subsidence, it is very important to consider the influence of groundwater exploitation and urban construction on the ground subsidence. According to the principle of conservation of mass, the model of ground subsidence caused by the ground subsidence caused by the non consolidation stratum under the building load is the same as that of the ground subsidence caused by underground mining [19]. But the land subsidence has coupling effect with the additive effect of groundwater exploitation and building load, it shows that the land sedimentation value with additive effect is lower than the sum of land sedimentation value with individual pumping and individual load under comparable condition[20], the quantitative expression of coupling effect has not been reported.

The effect of architectural complex on land subsidence.

The Chinese code for design of building foundation[21]gives a calculation method for subsoil deformation of building and considers that the time required for the subsoil deformation of building to stabilize relates to the compressibility of soil layer.(Housing and urban-rural development of the People's Republic of China, 2011) Scholars use the model test and numerical simulation to study the land subsidence caused by architectural complex, the land subsidence result caused by a single building calculated by current code is consistent with the actual situation, the ground subsidence caused by the architectural complex is different from the actual situation. The land subsidence caused by the architectural complex is influenced by the size of buildings, the volume ratio and the degree of dispersion, and the land subsidence area and the depth caused by architectural complex is greater than a single building [22]. The model test of land subsidence caused by architectural complex carried out by Tongji University shows that there are obvious superimposed effects in land subsidence. The superimposed effect increased with the increase of the volume ratio of the building, and the maximum settlement rate and the settlement amount had significant time effect [16][24]. Actually the mechanism of land subsidence caused by architectural complex is more complicated. The phenomenon of coexistence of most old and new buildings and the redevelopment and relocation of old buildings appear during the urban reconstruction, which give rise to superimposed effect of settlement and the effect of consecutive loading-unloading cycles and should also be concerned.

\section{The prediction of land subsidence}

The establishment of statistical model and physical model of land subsidence prediction is the two main methods for forecasting ground subsidence at home and abroad [7][23].

\section{Statistical model.}

Statistical model is based mainly on fuzzy neural network, grey theory and Poisson cycle [25][26][27]. Previous studies have proved that the grey theory model is suitable for the relatively uniform area of land subsidence [28]; artificial neural network model is suitable for the greater fluctuant area of land subsidence; and Poisson cycle model is suitable for the long-term predictions of land subsidence [9]. In practical application, because land subsidence is a complex process which is affected by many factors and the influencing factors has a complex nonlinear relation with 
subsidence, it is difficult to select the prediction method correctly and obtain the full data of land subsidence monitoring, which caused that the prediction accuracy of prediction model is difficult to guarantee.

\section{Physical model.}

Physical model includes water flow model and soil mechanics model. According to the coupling degree of those two models, it can be divided into two-step model, partly coupling model and fully coupling model [29]. In recent years, there are many new understanding of the physical model research, which is more reasonable to express all kinds of subsidence phenomenon, mainly includes the following aspects:

The pore water types of aquitard and the mechanism of seepage and deformation are closely related to buried depth, according to limitation water content, the deformation calculation model of aquitard in different buried depth was proposes [30][31][32].

The recent physical model considered that the deformation of every soil layer depends not only on the compressibility, but also on the thickness, which is more rational than the previous model which only depends on the compressibility of soil [1].

It was once believed that the completion of sandy soil deformation is instantaneous during the change of stress change, but the research of subsidence in Suzhou and Beijing shows that sandy soil has a similar creep property with cohesive soil [11][12] [33] [34].

Viscoelastic theory which is applied to analyze the question of land subsidence provides a new way for the simulation of a large-area land subsidence which has the characteristic of complex deformation [35].

The mechanism of the above physical model is clear, but the equation parameter is too complex, application is difficult and development is relatively slow.

The control of land subsidence and urban construction.

The previous focus of the research on the ground control is to restrict the exploitation of groundwater, adjust the level of water resources exploitation and artificial recharge [36]. Recently, with the deep research on urban construction and land subsidence, The control of land subsidence by the planning of urban construction has gradually attracted the attention of the academic community, and it is thought that the size of buildings, the volume ratio and the degree of dispersion are related closely with land subsidence [20][37]. Only limiting groundwater exploitation and reasonable planning urban construction can effectively control urban land subsidence [13][16][19]. But there is not yet a specific method to establish the optimum reference value of building size, volume rate, and dispersion degree with respect to land subsidence.

\section{Conclusions}

(1) In recent years, the new restrictive factors of land subsidence is engineering construction, in order to control urban land subsidence, Appropriate control of the urbanization process should be emphatically considered.

(2) The most urgent problem is to reveal the relationship between engineering construction, such as the size of buildings, the volume ratio and the degree of dispersion, and land subsidence, which will be beneficial to the environmental protection and the sustained development of the city.

\section{Acknowledgements}

In this paper, the research was sponsored by the National Science Foundation of China (Grant No. 41301015) and the Key Program of the Hebei Education Department (Grant No. ZD2015073).

\section{References}

[1] Xue Yuqun, Zhang yun, Ye Shujun. Research on the problems of land subsidence in China [J]. Geological Journal of China Universities,2006,29 (2):154-160

[2] Zhang Agen, Yang Tianliang. Latest progress review of research on international land 
subsidence [J]. Shanghai Geology, 2010, 31(4):57-63

[3] Peng Tao, Sun Tie, Song Jing, Wang Bingchen. Influence of urban land subsidence on deformation of water and sewer pipelines-a case study of the Xiangluowan area [J]. Geological Bulletin of China,2008,27(11):1882-1887

[4] Wei Gang, Yang Zefei, Lin Leilei. Study on surface settlement due to tunnel construction with shield in sandy silt area [J]. Journal of Wuhan University of Technology, 2012, 34(12): 93-96

[5] Liu Yi. Determination on the height of river flood dikes in China should consider land subsidence [J]. Shanghai Geology,1998, 3: 6-12

[6] Zhang Agen, Liu Yi, Gong Shilang. Overview of international land subsidence research [J]. Shanghai Geology, 2000: 1-7

[7] Liu Yi. Land subsidence research approaches and advent problems [J]. Earth Science Frontiers, 2001, 8(02):273-278

[8] Xue Yuqun, Zhang Yun, Ye Shujun. Land subsidence in China and its problems [J]. Quaternary Sciences,2003,23(6):585-593

[9] Cui Zhendong, TANG Yi-qun. Domestic and international recent situation and research of land subsidence disasters [J]. Northwestern Seismological Journal, 2007,29(3): 275-278

[10] Luo Zujiang, HUANG Xiaorui. Three-dimensional full coupling numerical simulation of groundwater exploitation and control of land-subsidence in region [J]. Journal of Hydrodynamics (Ser.A), 2009, 24:15-18

[11] Xu Haiyang, Zhou Zhifang, Gao Zongqi. Experimental study on coefficient of consolidation of land subsidence [J]. Chinese Journal of Geotechnical Engineering, 2011, 33(12): 1969-1973

[12] Xu Haiyang, Zhou Zhifang, Gao Zongqi. Experimental research of hysterics effect of land subsidence caused by water releasing [J]. Chinese Journal of Geotechnical Engineering,2011, 30 (S2):3595-3601

[13] Xu Yeshuang, Ma Lei, Shen Shuilong. Influential factors on development of land subsidence with process of urbanization in Shanghai [J]. Rock and Soil Mechanics, 2011 (Sup), 578-582

[14] Shi Weihua. The Applied Research of Gan-Chen Model in Geotechnical Engineering [J]. Shanghai Geology, 1999,(4):50-54

[15] Jie Yuxin, Gao Yan, Li Guangxin. Analysis on the land subsidence induced by city construction [J]. Geotechnical Engineering Technique,2007, 21(2): 78-82

[16] Tang Yiqun, Song Shoupeng, Chen Bin. Study of land subsidence rule of dense buildings under different floor area ratios[J]. Chinese Journal of Rock Mechanics and Engineering,2010, 29 (S1): 3425-3431

[17] Gong Shiliang. Effects of urban construction on the land subsidence in Shanghai [J].The Chinese Journal of Geological Hazard and Control, , 1998, 9( 2):108-111

[18] Yan Xuexin, Shen Guoping. Relationship between building density and land subsidence in Shanghai urban zone [J]. Hydrogeology and Engineering Geology, 2002, 29(6): 21-25.

[19] Zhao Hui, Qian Hui, LI Yuan. Land subsidence model under dual effects of groundwater pumping and construction loading [J]. Journal of Earth Sciences and Environment,2008, 30 (1):57-68

[20] Ding Demin, MA Fengshan, ZHANG Yamin. Characteristics land subsidence due to both high-rise building and exploitation of groundwater in urban area [J]. Journal of Engineering 
Geology,2011,19 (3):433-439

[21] GB50007-2011 Code for design of building foundation, Housing and urban-rural development of the People's Republic of China [S]

[22] Ling Qing, Zhang Qin, Qu Wei. Analysis of impact of ground load on city land subsidence after finite element model [J]. Journal of Geodesy and Geodynamics, 2012, 32(3):65-71

[23] Wu Qingzhong, Gao Weidong. Prediction of temporal and spatial distribution of land subsidence caused by groundwater exploitation based on BP network model [J]. Geotechnical Investigation \& Surveying, 2012, 40(1): 39-42

[24] Tang, Y.Q., Cui, Z.D., Wang J.X., et al. Application of grey theory-based model to prediction of land subsidence due to engineering environment in Shanghai [J]. Environ Geol, 2008, 55(3): 583-593

[25] Hiroshi P Sato,Kaoru Abe,OsamuOtaki.GPS2 measured land subsidence in Ojiya city Niigata Prefecture Japan[J].Engineering Geology 2003, (67):379-390

[26] Li Tao, PAN Yun, LOU Huajun. Application of the artificial neural network in land subsidence prediction in the urban area of Tianjin Municipality [J]. Regional Geology of China, 2005, 24(7):677-681

[27] Li Hongxia, ZHAO Xin-hua, CHI Hai-yan. Prediction and analysis of land subsidence based on improved BP neural network model [J]. Journal of Tianjin University, 2009,42(1):60-65

[28] Yan Jianfeng, Deng Kazhong. The precise grey model applied to the prediction of land subsidence [J]. Engineering of Surveying and Mapping, 2012, 21: 22-24

[29] Li Wenyun, Cui Yali, Su Chen. An integrated numerical groundwater and land subsidence model of Tianjin [J]. Journal of Jilin University (Earth Science Edition),2012, 42(3):805-813

[30] Li Wenping. Variation of pore water pressure and volume strain of saturated clayey soil during high pressure compression test [J].Chinese Journal of Geotechnical Engineering,1999, 21(6):666669

[31] Wu Qiang, Xie Hailan, Zhao Zengmin. Study on deformation mechanics of aquitard [J]. Journal of University of Science and Technology Beijing, 2006, 28(3): 207-210

[32] Wang Xiuyan, Liu Changli. Discussion on permeability of deep clayey soil [J]. Chinese Journal of Geotechnical Engineering, 2003, 25(3): 308- 312

[33] Wang Fei, Miao Linchang. Study of long-term deformation characteristics of sand aquifers foreland subsidence caused by groundwater withdrawal [J]. Chinese Journal of Rock Mechanics and Engineering, 2011,30(S1): 3135-3140

[34] Zhang Yun, Xue Yuqun, Shi Xiaoqing. Study on nonlinear creep model for saturated sand [J]. Rock and Soil Mechanics,2006,26(12):1869-187

[35] Ye ShuJun, Xue YuQun, Wu JiChun. Land subsidence modeling based on the modified Merchant model: A case study of Shanghai. Journal of Nanjing University (Natural Sciences),2011,47(3):291-298

[36] Wu Jianzhong, Wang Hanmei, Yang Tianliang. Experimental research on artificial recharge to shallow aquifer to control land subsidence due to construction in Shanghai city [J]. Geoscience, 2009, 23(6):1194-1200

[37] Song Shoupeng, Tang Yiqun. Best floor area ratio of high density buildings based on archeological theory [J]. Journal of Central South University (Science and Technology), 2012, 43 (6): $2349-2356$ 